\title{
Evaluating arguments and making meta-arguments
}

\section{Daniel H. Cohen Colby College}

\begin{abstract}
This paper explores the outlines of a framework for evaluating arguments. Among the factors to take into account are the strength of the arguers' inferences, the level of their engagement with objections raised by other interlocutors, and their effectiveness in rationally persuading their target audiences. Some connections among these can be understood only in the context of meta-argumentation and meta-rationality. The Principle of Meta-Rationality (PMR)-that reasoning rationally includes reasoning about rationality-is used to explain why it can be rational to resist dialectically satisfying arguments or accept logically flawed ones.
\end{abstract}

Résumé: On explore les grandes lignes d'une approche pour évaluer des arguments. Parmi les facteurs dont on tient compte sont la force des inférences, le niveau d'engagement envers des objections, et l'efficacité de persuader rationnellement un auditoire visé. On peut comprendre certains rapports parmi ces facteurs seulement dans un context de méta-argumentation et de métarationalité. On emploie le Principe de MétaRationalité (PMR), selon lequel la réflexion rationnelle exige une réflexion sur la rationalite, pour expliquer pourquoi il peut être rationnel de ne pas avancer certains arguments dialectiquement avantageux et d'accepter certains qui sont défectueux.

Keywords: argument, rationality, logic, rhetoric, dialectic.

\section{Introduction}

There are many ways to take the measure of an argument, many vocabularies and criteria available to help us answer the question: Is the argument a good one? There are many questions contained in this one. Ethics, politics, aesthetics, epistemology, psychology, jurisprudence, and many other disciplines, all have something to contribute. For the purpose of rational persuasion, ${ }^{\prime}$ however, the real core of argumentation theory rests on the tripod of logic, rhetoric, and dialectic.

The different approaches to argument are not independent of one another. Logic provides fodder for epistemological justifications or condemnations of argument forms; rhetorical analyses might well include or intersect aesthetic considerations; psychological explanations of why certain valid argument forms invite suspicion while some invalid ones generally meet with assent would be relevant for dialectic; and so on. Even among the tripartite core, there are important connections: deductively valid inferences from well-warranted premises generally make for dialectically satisfying arguments, and dialectical closure is generally rhetorically compelling. 
For all their connections, logical, dialectical, and rhetorical criteria for taking the measure of arguments are separable, both conceptually and practically. Neither logical validity nor dialectical success entails the other. Moreover, neither one entails, or is entailed by, rhetorical effectiveness. It is possible, therefore, for an argument to pass muster logically and rhetorically, say, but not dialectically: a cogent argument may succeed in convincing its audience despite their lingering questions. And it is equally possible to argue rhetorically and dialectically well, but not logically: logical flaws that escape both the arguer and the audience will not detract from its effectiveness as a tool for rational persuasion. Indeed, all the combinations are possible. It will be helpful, even at the risk of pedantry, to articulate the different standards more clearly and to consider systematically all possible combinations. The exercise pays off in the end, with implications of great philosophical significance concerning the concepts of argumentative closure, rationality, and philosophy itself.

\section{\$1 Evaluating Arguments}

Logic, dialectic, and thetoric can be thought of as forming a three dimensional coordinate systems for evaluating arguments. Each is needed to track a different part of the social-linguistic complexes that constitute arguments. The logical axis evaluates the inferences that the participants make (the components of "arguments ${ }_{1}$ "). The dialectical axis is for the disputants' engagement with their opponents (the "dialectical tier" of "arguments ${ }_{2}$ "). And the rhetorical axis measures the efficacy of the arguments (e.g., the effects on the "audience"4).

In a purely deductive context, the logical axis could be replaced by a bivalent function, the two values being "valid" and "invalid," for assessing inferences. But even for evaluating purely formal arguments, more is needed. The premises have to be weighed apart from their use in the inferences at hand, so the evaluative vocabulary needs to be enriched by "soundness" and "unsoundness." In real-life contexts, logic is better conceived as providing a sliding scale measuring the relevance, sufficiency, and acceptability-Johnson and Blair's "R-S-A test"-of the premises as reasons for the conclusion. ${ }^{5}$ Thus, "cogency" is a better positive value for the logical evaluation of arguments, and indeed this is the conceptual ground often claimed by critical thinking, informal logic, and formal logic texts. The traditional identification of the study of inferences with the study of arguments can be justified, however, only by a very narrow conception of argument. (If the inferential evaluation were thought of numerically, then the 0 -point could be complete premise-irrelevance; deductive validity would be the positive limit; and negative , values could be assigned to premises that would serve better as counter-considerations. ${ }^{6}$ )

The dialectical perspective would properly have to include two or more measures because dialectical engagement necessarily involves two or more arguers.? An arguer has argued well dialectically when all of the objections and questions 
that have been raised have been answered satisfactorily. This standard applies to all the participants in an argument. Typically, this is all that we are concerned with in the dialectical evaluation of arguments. The shift in focus from arguments to arguers naturally focuses on the agent producing the argument. However, there are several distinct roles for arguers in arguments: proponents and opponents, as well as arbiters, spectators, and other sorts of audiences. Therefore, different criteria are needed. Specifically, it is proponents who need to respond to objections; their opponents need to raise those objections. An opponent is dialectically praiseworthy when all the objections that really should be raised against a proponent's argument are raised, but no more, and any points that need to be clarified in order for the audience-including the opponent-to understand the argument have been questioned. And insofar as audiences have an interactive role in argumentative discourse, they too serve as the opposition and thus have an obligation to object to shoddy reasoning, dubious premises, and unclear statements. ${ }^{8}$

An argument may, of course, pass dialectical muster without being logically valid, and even deductively valid arguments can be questioned.

The rhetorical perspective examines an argument's effects on the audience. Of course, successfully persuading the audience to accept a conclusion is one of the possible effects of an argument. Thus, for most purposes, this third perspective is the most important, if only because the argument-as-war model remains a dominant paradigm for thinking about arguments. ${ }^{9}$ In an adversarial setting, persuasion translates as victory. To be sure, rhetoric is not concerned solely and wholly with winning arguments. Moreover, there are ways to win arguments that are not rhetorically acceptable. Some dialectically effective strategies, such as filibusters, are rhetorical transgressions."Winning" an argument without persuading the target audience, e.g., by force or parliamentary subterfuge, is not really an argumentative victory per se. Rather, it is a victory in a different competition. Effective communication, tailoring an argument to the audience at hand, and respecting the social context of the argument are all proper concerns for rhetoric. This is not to deny that the "agonistic" concern--winning and losing-is a part, but simply to affirm that it is just a part. ${ }^{10}$

The outline of a three-part evaluation scheme for arguments is now visible. Arguers and their arguments can succeed or fail in three separate ways. Arguments can be cogent or not; they can be dialectically satisfactory or not; and they can be rhetorically - agonistically—successful or not. " These determinations are all independent, to some degree. If "winning" and "losing" are taken as the relevant agonistic outcomes, ${ }^{12}$ and successful dialectical engagement is called "satisfying," then all the possibilities are displayed in the table on the following page.

The possibilities range from fully praiseworthy arguments, (1) - well reasoned arguments that meet all objections and justifiably convince their hearers--to abject argumentative failures, (8)-illogical configurations of dogmatic assertions that deservedly fail to persuade. It is not particularly hard to come up with examples for each of the eight possibilities. The context of a courtroom provides a rich vein 
to mine in the search for instantiations. It is a setting in which winning and losing are precisely defined by the jury's verdict, so the agonistic valuation is unequivocal. ${ }^{13}$ The dialectical value should measure the level of satisfaction the jurors have with the attorneys' arguments-which need not track their eventual judgment. Because the standard for convictions is high in criminal cases, jurors may vote to acquit even though they have unanswered objections to the defending attorney's arguments. Alternatively, they may return a guilty verdict despite some confusion about some parts of the prosecutor's case. That is, the dialectical and rhetorical evaluations may diverge.
Logic

$$
\checkmark \text { Cogent }
$$
$X$ Not cogent $\checkmark$ Cogent
$X$ Not cogent $\checkmark$ Cogent
$X$ Not cogent $\sqrt{ }$ Cogent
$X$ Not cogent
Dialectic
$\sqrt{ }$ Satisfying
$\checkmark$ Satisfying
$X$ Unsatisfying
$X$ Unsatisfying
$\sqrt{ }$ Satisfying
$\checkmark$ Satisfying
$X$ Unsatisfying
$X$ Unsatisfying
Agonistic
$\sqrt{ }$ Winning
$\sqrt{ }$ Winning
$\sqrt{ }$ Winning
$\sqrt{ }$ Winning
$X$ Losing
$X$ Losing
$X$ Losing
$X$ Losing

Of the eight possibilities, two are especially noteworthy and deserve some separate consideration here: ${ }^{.14}$ categories (4) and (5), arguments that should not win but do, and arguments that should win, but do not.The former are unsound, unsatisfying arguments that nonetheless carry the day; the latter are cogent, satisfying arguments that nonetheless fail. In both cases, the apparent anomaly can be explained away by referring to the audience. The former class includes those filibusters that count as arguments (as distinct from those that are better understood as preventing argument ${ }^{15}$ ). The strength, and eventual success, of a filibuster depends on its audience's weakness. A logically and dialectically deficient argument could also produce the same result with an unduly acquiescent audience. The theoretical possibility of the latter class can also be explained in terms of the audience's shortcomings. There are audiences that simply do not listen to reason, viz., unreasonable, unhearing, adamant, or incompetent ones.

We think that logically cogent and dialectically satisfying arguments ought to be successful, and when they are not, something has gone wrong. Finding fault with the audience preserves our sense of what is argumentatively right and proper. Yet, there is another sort of case that precludes that comfortable complacency. The anomaly of good-but-losing arguments can just as easily result from audience rationality and competence as from audience irrationality or incompetence. In general, it may well be a sign of strength to bow before a good argument, ${ }^{16}$ but in some circumstances, it can also be a sign of strength to resist an argument-even a good argument! 
To see how this situation can arise, consider the following sort of example, from category (6)-an unsound argument that is unpersuasive even though it is dialectically satisfactory: Suppose an argument is presented leading to the conclusion that $1=0 .{ }^{17}$ Obviously, the accompanying "proof" cannot be cogent. It must be fallacious at some point, but if the error in reasoning is subtle, it might easily be missed. If the audience is sophisticated enough to recognize the fallacy, the argument will not work. It can persuade only if the audience is completely gullible. But what if the audience is not so incompetent as to accept the conclusion, but not quite adept enough to recognize the fallacy or raise any further objections? In that case, the stubborn refusal to accept the conclusion despite the reasons offered and despite the absence of any objections seems altogether reasonable.

Even relatively sophisticated arguers will not always be in position to determine the objective soundness of an argument definitively. There are many factors at play, in addition to logical acumen, including familiarity with the subject matter and the availability of information. Accordingly, there is a way to generalize from the case above. Suppose an audience is presented with an argument for an altogether unacceptable conclusion. Various objections are raised, and rebutted. Alternative interpretations of the premises are considered and rejected; divergent inferences from those premises are similarly closed off; and no other explanations appear at hand. Still, for whatever reasons, the conclusion cannot be accepted-perhaps because there is another, equally compelling and undefeated argument for its contrary ${ }^{18}$ or perhaps because the conclusion itself is so unpalatable that one literally cannot commit to it. ${ }^{19}$ In such a case, it need not be unreasonable to resist the argument. One can adopt the attitude that there must be something wrong with it somewhere, and that the problem will be discovered in the course of time. Indeed, this is precisely the stance that was adopted by physicists when confronted with evidence and arguments showing that light was both a particle and a wave. The faith that eventually something would give way-although it was unknown just what would - was not unreasonable.

The reason this sort of case deserves special attention is that it describes a situation that is all-too-common in philosophy. Consider, for example, the variety of responses to Berkeleyan Idealism. Philosophical discussions often begin with the question, "What is wrong with Berkeley's arguments?" instead of "Is something wrong with Berkeley's arguments?" While there may be something odd about this for a discipline that prides itself on leaving no assumptions unexamined, it is not irrational per se. A similar comment can be made about the history of responses to Anselm's Ontological Argument. For many philosophers, the natural and proper approach to the argument seems not to wonder whether there is something wrong with it, but rather to debate about just what is wrong with it. Again, while it may be unphilosophical, it is not necessarily irrational for someone to take this positionespecially if the question of God's existence has already been visited many times, personally and deeply. 
Indeed, this sort of situation is so common as to be the norm in philosophy. How often do philosophical arguments actually succeed in persuading determined opposition? Does this mean that determined philosophical opposition is, in general, a sign of irrationality? Or should we conclude that despite the time and energy philosophers invest in arguing, there just are not that many good philosophical arguments? (For some, these could stand as examples of literally unacceptable conclusions!) The point of the above example is to emphasize that these are not the only options. Able arguers presenting cogent arguments to rational audiences might still be met with disagreement. A measure of logic, pragma-dialectically mixed with a dash of rhetoric is not, unfortunately, a surefire recipe for agreement.

\section{\$2 Meta-Rationality and Argumentation}

In general, we assume that there will always be counter-arguments, if only we are clever enough to find them, that will deliver us from the clutches of any really repugnant arguments that confront us. While this may be more true of philosophical arguments than others, it does apply in some measure to all arguments. Admittedly, philosophical arguments are atypical in many ways. They do not provide a safe basis for generalizing about all argumentation. They do, however, serve to bring some features of argumentation into higher relief. In philosophical contexts, we often engage in this sort of meta-argumentation, arguing about arguments, quite explicitly. In other contexts, it may be more implicit. In either case, we are appealing to a fundamental assumption about reasoning and argumentation. It can be called the "Principle of Meta-Rationality":

(PMR) Part of reasoning rationally is reasoning about rationality.

This principle is not simply an article of rationalist faith. It embodies the fundamental assumptions about the practice of argumentation. It is both a principle of rationality and a principle about rationality, a principle and a meta-principle, because it concerns both reasoning and its products. Arguments are, of course, preeminent products of reasoning, so they themselves can be the subjects of other arguments. An immediate corollary to the PMR, then, is that part of arguing rationally is arguing about rationality ${ }^{20}$

There are profound consequences for argumentation theory springing from the PMR. The same principle that justifies argumentation also justifies our resistance to unpalatable arguments. Such resistance can be the conclusion of the following, perfectly reasonable, but generally unarticulated, "meta-argument" about arguments and reason:

(1) This argument seems cogent but has an unreasonable conclusion;

(2) Cogent arguments do not lead to unreasonable conclusions;

So, (3) this argument must, in some way, be fallacious, i.e., it must fail in some way-even if I do not yet see how or why. 
There are two points to note about the Meta-Argument for Resisting Good Arguments-call it the "MARGA move." ${ }^{2 t}$ First, it is, for good or ill, always available, which is just another way of saying that everything is arguable. Meta-rational thinking is indeed part of thinking rationally. Argumentation is precisely for those areas in which beliefs are not compelled. ${ }^{22}$ And if arguments do not force acceptance, there will be room for dissent. The second point to note is that there are occasions when the MARGA move is undeniably a rational strategy. However, that only serves to raise another question (sending us still higher into the "meta-sphere"): When is it rational to use MARGA to reject an argument? Context matters. We do not approach arguments with a tabula rasa. Nor are arguments isolated episodes in our intellectual lives (or, for that matter, our spiritual, emotional, social, political, and psychological lives). Recourse to this meta-argument is rational at least in those cases in which, to borrow some language from William James, the question is effectively "closed" against the putative conclusion. ${ }^{23}$ Since the proposition that $1=0$ is a closed issue, any argument leading to that conclusion certainly invites a MARGA response whenever a more specific identification of an argumentative error cannot be supplied. For James, the concept of closure was relative to individual believers. For the purposes of argumentation theory, it also needs to come in degrees - the way that argument strength and rationality do. An argument against a weakly held belief does not need to be as strong as an argument against a strongly held belief to forestall recourse to MARGA. Conversely, it is less rational to invoke MARGA against a strong argument on behalf of a weakly held belief.

There is a counterpart situation with respect to bad arguments that also flows from the PMR. A Meta-Argument for Accepting Bad Arguments-a "MAABA defense"-can justify acceptance of a conclusion despite the flaws in the supporting (ground-level) argument:

(1a) The argument as it stands seems fallacious, but it has a reasonable conclusion;

(2a) All reasonable conclusions can be supported by cogent arguments; So, (3a) the argument can be made cogent-even if I do not yet see how.

This line of reasoning often serves as an apology for existing beliefs. It might better be termed the "Tertullian Defense" after the 2nd-3rd century Latin A pologist credited with the prototypical MAABA defense: the "credo quia ineptum" defense of his faith. ${ }^{24}$ Despite Tertullian's own case, the MAABA defense need not be irrational. For example, it is not hard to imagine an intuitive, creative, and rational mathematician who has great confidence in her theses before she is able to construct satisfactory proofs. Despite the flaws that her colleagues might find in her first attempts at proof, an induction on her past successes might support her belief in the next proposed theorem. ${ }^{25}$ The flawed "proof" might be taken as a promissory note to be redeemed at a later date, e.g., as the starting point for further attempts at proof or as a heuristic vehicle in its own right. Even if the "context of discovery" is carefully distinguished from the "context of justification," there can be independent grounds for the reliability of the processes of the former. 
If the meta-logical space around arguments includes these meta-arguments for overriding arguments, then perhaps we need meta-arguments to reinforce the (ground-level) arguments and counter the meta-arguments. A little exploration of that space reveals that the PMR can provide such arguments, but with a curious twist. Consider first the Meta-Argument for Accepting Good Arguments, or MAAGA:

(1b) This argument seems cogent and the conclusion is reasonable;

(2b) Apparently cogent arguments with reasonable conclusions usually are genuinely cogent;

So, (3b) it is unlikely that flaws will be found: accept the conclusion.

Do we implicitly make this argument every time we accept any argument?

I suspect that most of the time we do not reason that way. There is no call to articulate the second premise, (2b)-unlike the counter-consideration presented by (2). When we hear an argument for a proposition, a course of action, or a conclusion of another sort, we weigh the reasons that are presented. If we are responsible and competent in our role as the audience to an argument, we also consider whatever other information is relevant and available. If the pros duly outweigh the cons, then we accept the conclusion. We do not, in general, let the mere possibility of additional counter-considerations serve as an excuse not to accept it. We could, of course, because that possibility is a permanent feature of the landscape around (non-deductive, non-formal) arguments: everything is arguable. We provide the meta-argument only as needed, e.g., if our decision is challenged, if there are residual doubts, or if there are other motivating factors. Apparently, philosophical partisanship can be one such factor.

It is quite within proper argumentative practice that we do not routinely use the meta-argument for accepting good arguments. That way leads to Lewis Carroll's infinite regress: if in order to accept an argument, I need to accept this other, metaargument, then there would have to be a meta-meta-argument for accepting the first meta-argument! ${ }^{26}$ Ordinarily, we need not-and, arguably, should not-ascend to that meta-level to accept other arguments. An argument for a proposition, $p$, answers the question of why one should accept $p$. That is usually the question at hand, and a good argument is a good answer to that question. The question of whether the presence of good reasons for accepting $p$ is a good reason for accepting $p$ is, in the normal course of events, otiose. The principle of meta-rationality, PMR, breaches the walls between arguments and meta-arguments. Yet, as will be seen, there are times when it is rational to resort to explicitly meta-level reasoning.

The complement to MAAGA would invoke a Meta-Argument for Rejecting Bad Arguments, a MARBA move:

(1c) This argument seems fallacious and the conclusion is unreasonable;

(2c) Arguments for unreasonable conclusions usually are really fallacious; 
So, (3c) it is unlikely that the argument can be fixed: do not accept the conclusion.

This meta-argument, too, merely repeats and reinforces the judgment made concerning the first argument. But there is an asymmetry with MAAGA. This does not lead to an infinite regress. (It would, however, quickly lead to paradox if it were itself a bad argument, if the argument applied to itself, and if the conclusion were to call for rejecting, as opposed to simply not-accepting, the conclusion at hand.)

When should these meta-arguments be used? When do they count as good arguments? In part, these questions have to be answered by the purposes the (object-) arguments serve. The first two meta-arguments, MARGA and MAABA, have important, deeply conservative, roles to play. They serve as the final line of defense in preserving pre-existing beliefs against arguments. This is where the standards for belief revision need to be higher than the standards for belief acquisition. ${ }^{27}$ Their use is justified when these purposes come into play. In contrast, the other two, MAAGA and MARBA, are largely redundant in most argumentation contexts. They do, however, have a visible role in self-conscious, philosophical argumentation. More significantly, these reinforcing arguments are at home in self-reflective deliberation- "The argument seems good; should I accept it? How would I respond to that objection?"- - the context in which the distractions created by the competitive and social aspects of argumentation are largely absent. Of course, the same can also be said for the earlier pair as well, which points to an important feature: all of these arguments are really arguments with oneself. The use of the meta-argument against an undefeated argument for $p$, for example, is part of one's own interior dialogue, rather than part of the exterior argument with the proponent of $p .{ }^{28}$ That is, the audience of the meta-argument is usually the meta-arguer himself.

Once the audiences for these meta-arguments has been identified, these instantiations of the PMR can themselves be evaluated as successes or failures, as context determines, using the earlier tripartite coordinate system of logic, rhetoric, and dialectic. The call for these sorts of arguments is most pressing whenever there is a particularly tenacious (meta-)arguer present. That, of course, is something philosophers are wont to be, which helps to explain why these arguments seem so characteristically philosophical. It is one of the reasons why conclusive dialectical success is so elusive in philosophy.

\section{Notes}

1 There can be other purposes to argument, necessitating other criteria. See R. Johnson 2000 p.191ff. for identifying rational persuasion as the relevant one.

${ }^{2}$ See O'Keefe 1977 for argument, and argument ${ }_{2}$.

${ }^{3}$ R. Johnson 1996, Ch. 6 .

4 See e.g., Perelman and Olbrechts-Tyteca 1969, Govier 1999, and Tindale 1999. 
${ }^{5}$ Johnson and Blair 1994, pp. 54f. Similar criteria can be found in other informal logic and critical thinking texts, e.g., the "ARG conditions" in Govier 1992 pp.69ff. Johnson 2000 adds a truth criterion.

${ }^{6}$ Hans Hansen (1999) raised the following question: Consider a sequence of arguments, each from a single premise (or the conjunction of several) to a constant conclusion. They can be arranged in ascending order of the strength of the premises:

$$
\cdots \frac{\mathrm{P}-2}{\mathrm{C}} \quad \frac{\mathrm{P}-1}{\mathrm{C}} \quad \frac{\mathrm{P}[=\mathrm{C}]}{\mathrm{C}} \quad \frac{\mathrm{P}+1}{\mathrm{C}} \quad \frac{\mathrm{P}+2}{\mathrm{C}} \cdots
$$

The inductive strength of the argument increases with the strength of the premise. Once the premise matches the conclusion, at, say, $\mathrm{P}$, deductive validity has been reached. What happens if the premise gets stronger still? There is no accepted terminology for "more than deductively valid" or "deductively more valid," but there is conceptual room for a logical counterpart to the causal concept of overdetermination. In some contexts, however, this could be the rhetoricalalbeit neither logical nor dialectical-fallacy of "Beating a dead horse."

'It would be more accurate to say that dialectical engagement involves two or more argumentative roles, rather than two or more arguers, since a single arguer can be both proponent and opponent, e.g., when someone argues with herself. Similarly, someone can be both the opponent and the target audience for an argument.

${ }^{8}$ Both the concept of a "universal audience," from Perelman and Olbrechts-Tyteca 1969, and the concept of "model interlocutors," from Blair and Johnson (Ch. 5 in R. Johnson 1996), while developed as part of the standards for good arguments, can also be inverted to measure bad audiences, thereby defining a category of "audience fallacies" or "antagonist fallacies," distinct from the more traditional focus on "protagonist fallacies." See also R. Johnson 1999.

"Lakoff and Johnson 1980 use the argument-as-war metaphor as an example for discussing metaphors. It has been subjected to a number of critiques by argumentation theorists as a model for arguments, including Nozik, 1981, Ayim 1991, Cohen 1995, and Gilbert 1997.

${ }^{10}$ Perelman and Olbrechts-Tyteca 1969 use the term "eristic" for much the same purpose. It is adopted by Gilbert 1997, inter alia. Van Eemeren et al. 1996 use the term "debate." "Agonistic" is preferred here because the issue here is specifically the competitive aspect of a contest, as opposed to the more general notion of controversy implied by the former and the more artificial and formalized context suggested by the latter.

"If this tripartite scheme for argument success is inverted, it provides a taxonomy for argument failings-fallacies. Inferential flaws, such as Hasty Generalization, would be "logical fallacies"; flaws in communicative interaction, such as ignoring or misunderstanding objections, would be "dialectical fallacies"; and negative or counterproductive strategies, e.g., alienating the audience, could be classed as "rhetorical fallacies." Traditional texts focus on the first of these, while the pragma-dialectical school focuses on the second, and the third is addressed by more classical rhetoricians.

12 The substitution of "success at rational persuasion" for "winning," and "failure at rational persuasion" for "losing" does not materially change the possibilities, but it muddies the waters separating the dialectical and rhetorical components. Unless rational persuasion is taken to be an all-or-none outcome, it will be possible to be rationally persuaded but not dialectically satisfied. One can be rationally persuaded to go along with a plan of action, for example, while still harboring doubts and while questions still linger. This is a corollary to the claim that beliefsincluding those of which we have been persuaded by good argument - can always be reinforced. The use of "winning" here is meant to bring the difference into higher relief, insofar as it covers everything from earning begrudging acceptance to extracting reluctant acknowledgement and achieving zealous conversion.

" This is also provides a clear distinction between the narrowly agonistic evaluation (winning versus losing) and a broader rhetorical evaluation (performatively). One can imagine a case in 
which a lawyer produces an exceptionally strong argument and presents it elegantly and forcefully, but still loses-because, say, of a biased or even rigged jury. The lawyer's performance cannot fairly be faulted from a rhetorical perspective, even though the argument still lost. We should be able to say that the "art of rational persuasion" was exemplified excellently even though no one was rationally persuaded. Admittedly, this sounds rather uncomfortably like the doctor who claimed that the operation was a success even though the patient died.

${ }^{14}$ Providing examples for the other six combinations is left to the reader (albeit, perhaps as an exercise to assign in class).

${ }^{15}$ Filibusters that prevent engagement are dialectically fallacious; filibusters (or the threat thereof?) used to win arguments might be subsumed under the argumentum ad baculum rubric, a logical fallacy.

${ }^{16}$ Francisca Snoeck-Henkemans, Poster for the 4th International Conference on Argumentation, International Society for the Study of Argumentation, Amsterdam, June 16-19, 1998.

${ }_{17}$ There are several commonly offered spurious proofs. One such is: Let $A=1$ and $B=1$. Thus, $A=B$. Then, multiplying both sides by $A: A^{2}=A B$. Subtracting $B^{2}$ from both sides yields: $A^{2}-B^{2}=A B-B^{2}$. Factoring, we have, $(A+B)(A-B)=B(A-B)$. Divide both sides by $(A-$ $B$ ) to get $A+B=B$, and then subtract $B$ from each, proving that $A=0$. Since $A=1$, we have $1=0$. The error is in the fourth step, dividing by $(A-B)$, an amount equal to 0 .

${ }^{18}$ Gilbert Ryle's "dilemmas" would fit this characterization. See Ryle 1954, Chapter 1.

${ }^{19}$ See Quine's definition of "paradox" in the title essay in Quine 1976. Nozick's discussion of philosophy's need to be dignity-preserving is another example of this sort of phenomenon, in the opening chapter of Nozick 1981.

${ }^{20}$ Argumentation, along with rationality, is a "fixed point" under the "meta-" operation: metareasoning about reasoning is still reasoning; and meta-arguments are still arguments. This feature is characteristic of philosophy, too: meta-philosophy is part of philosophy.

${ }^{21}$ This way of formulating the argument was suggested in conversation by my colleague Robert McArthur, but he is not responsible for the ungainly name.

${ }^{22}$ This point is made by Perelman and Olbrechts-Tyteca 1969, p. 5.

${ }^{23}$ James 1897.

${ }^{24}$ This is the version cited by Hyman and Walsh, 1983, p.10, although it is more often cited as "credo quia absurdum." Both can be translated as, "I believe because it is absurd."

${ }^{25}$ The early career mathematician S. Ramanujan exemplifies this. He had great faith in his theorems, although he was often, in the beginning, unable to supply the sort of rigorous proofs that would satisfy his colleague G.H. Hardy or the rest of the mathematical community. Henri Poincaré could also be a model for this. He claimed that his theorems often came to him in dreams. Proofs came later.

${ }^{26}$ See Carroll 1895.

${ }^{27}$ See Harman 1984.

${ }^{28}$ See Perelman and Olbrechts-Tyteca $1969, \$ 9$.

\section{References}

Ayim, Maryann, "Violence and Domination as Metaphors in Academic Discourse," in Selected Issues in Logic and Communication, T. Govier, ed. (Belmont, CA: Wadsworth Publishing Co., 1988).

Carroll, Lewis, "What the Tortoise said to Achilles," Mind, vol. 4 (1895), pp. 278-280. Reprinted in Readings on Logic, 2nd edition, I. M. Copi and J. A. Gould, eds. (New York: Macmillan Company, 1972). 
Cohen, Daniel H. "Argument is War... and War is Hell: Philosophy, Education, and Metaphors for Argumentation," Informal Logic, Vol. 17, No. 2 (Spring 1995), pp. 177188.

Eemeren, Frans H. van, et al. The Fundamentals of Argumentation Theory (Mahwah, NJ: Lawrence Erlbaum Associates, Publishers, 1996).

Gilbert, Michael, Coalescent Argumentation (Mahwah, New Jersey: Lawrence Erlbaum Associates, 1997).

Govier, Trudy, A Practical Study of Argument, 3rd edition (Belmont, CA: Wadsworth Publishing Co., 1992).

Govier, Trudy, Philosophy of Argument (Newport News, VA: Vale Press, 1999).

Hansen, Hans V. "Argumental Deduction: A Programme for Informal Logic," in F.H. van

Eemeren, R. Grootendorst, J. A. Blair, C.W. Willard (eds.), Proceedings of the Fourth International Conference of the International Society for the Study of Argumentation, pp. 311-316 (Amsterdam: Sic Sat, 1999).

Harman, Gilbert, "Positive Versus Negative Undermining in Belief Revision," Noûs, Vol. XVIII (1984), pp. 39-49.

Hyman, Arthur and James J. Walsh, eds., Philosophy in the Middle Ages, 2nd ed. (Indianapolis: Hackett Publishing Company, 1983).

James, William, The Will to Believe (New York: Longmans, Green, \& Co., I897). Reprinted.

Johnson, Ralph, The Rise of Informal Logic (Newport News, VA: Vale Press, 1996).

Johnson, Ralph, "More on Arguers and their dialectical obligations," Argumentation at the Century's Turn (CD rom), Proceedings of the Ontario Society for the Study of Argumentation, C. Tindale, ed., 1999.

Johnson, Ralph, Manifest Rationality: A Pragmatic Theory of Argument (Mahwah, NJ: Lawrence Erlbaum Associates, 2000).

Johnson, Ralph and J. Anthony Blair, Logical Self-Defense, United States Edition (New York: McGraw-Hill, Inc.1994).

Lakoff, George and Mark Johnson, Metaphors We Live By (Chicago: University of Chicago Press, 1980).

Nozick, Robert, Philosophical Explanations (Cambridge, MA: Belknap Press, 1981).

O'Keefe, D. J., "Two Concepts of Argument," Journal of the American Forensic Association, $13(1977)$ pp. 121-128.

Perelman, Chaim and L. Olbrechts-Tyteca, The New Rhetoric (Notre Dame, IN: University of Notre Dame Press, 1969).

Quine, W. V. O., The Ways of Paradox and Other Essays, rev. ed. (Cambridge, MA: Harvard University Press, 1976).

Ryle, Gilbert, Dilemmas (Cambridge: Cambridge University press, 1954).

Tindale, Christopher, Acts of Arguing: A Rhetorical Model of Argument (Albany: State University of New York Press, 1999). 